\title{
Analysis on the Behavioral Orientation of the Herdsmen in the New Rural Construction and Its Influencing Factors
}

\author{
--Based on the Survey of the Pasturing Area in Northwest Sichuan
}

\author{
Wenxiu Zhang (Corresponding author) \\ Department of Economic Management, Sichuan Agricultural University \\ Hui Min Road 211, Wenjiang District, Chengdu, 611130, Sichuan, China \\ Tel: 86-186-2813-6673 E-mail: cndzwx@163.com
}

Qi Yin

Department of Economic Management, Sichuan Agricultural University

Hui Min Road 211, Wenjiang District, Chengdu, 611130, Sichuan, China

Tel: 86-186-2806-2705Ｅ-mail: 25575670@qq.com

$\begin{array}{lc}\text { Received: July 21, } 2011 & \text { Accepted: August 15, } 2011 \quad \text { Online Published: December 29, } 2011 \\ \text { doi:10.5539/jas.v4n3p85 } & \text { URL: http://dx.doi.org/10.5539/jas.v4n3p85 }\end{array}$

\begin{abstract}
As a construction body of the new rural construction, herdsmen's behavioral orientation would have a major impact on the process of the new rural construction. The herdsmen's production behavior, consumer behavior, social behavior and environmental behavior are formulated in the new rural construction based on the field survey of 170 rural herdsmen in the pasturing area of northwest Sichuan by using the qualitative methods and statistical analysis. This paper analyzes the influencing factors of herdsmen's behavior orientation with some proposed policy suggestions.
\end{abstract}

Keywords: Herdsmen, New rural construction, Behavioral orientation, Influencing factors

\section{Introduction}

Being one of the five major pastoral areas and the second largest Tibetan residence of China, the northwest of Sichuan Province is an important animal husbandry base in Sichuan Province. With the advancement of the new countryside construction, many experts and scholars had emphasized that the farmers should play the main role in the construction of new rural and as the key to the success of new rural construction (Gu, 2009; Duan, 2010; Zang, 2011), but little research has been made in this area with most concern on agricultural areas. As the main building of new rural pastoral, pastoral orientation behavior will have a major impact on the process of building new countryside. Therefore, this article analyzes the herdsmen's production behavior, consumer behavior, social behavior and environmental behavior in the new rural construction based on the field survey of 170 rural herdsmen in the pasturing area of northwest Sichuan.

Affecting by language barriers, literacy and other factors, only 170 questionnaires were recovered among 220 in this study; the $88.2 \%$ samples were made by male for the home headed almostly by men in Tibetan pastoral areas and $71.2 \%$ samples were made by the age of the person between $21-50$ years old, to obtain a better answer to the question about the authenticity. However, respondents who have generally low education (especially not attend school as high as 57.1\%) may cause a certain impact on the accuracy of the data (See Table 1).

\section{The Behavior Orientation of the Herdsmen in the New Countryside Construction}

Behavior is the individual performance of the external action; behavior is the variety of selection decisions in the production and living activities of the pastoral nomads. The construction of new countryside is a systematic project, and this project can be divided into four sub-systems which are production, consumption, social and environmental, according to "the development of production, affluent life, rural civilization, clean village, and democratic management" of the 20 characters principle (Ze et al., 2008). Among them, the "the development of 
production" is the production subsystem; the "affluent life" is the category of consumer subsystem; "rural civilization, democratic management" is a social subsystem; "clean village" is the environmental subsystem. Therefore, the behavior of herdsmen in the new rural construction can be divided into the production behavior, consumer behavior, social behavior and environmental behavior.

\subsection{Production Behavior}

\subsubsection{The herdsmen's Scale of Operation}

The herdsmen's scale of livestock operations can be reflected through scale of grassland and the number of raising (See Table 2). In the survey of 170 samples, there are 5 samples show that the scale of grassland of less than $4 \mathrm{hm}^{2}$ of lawn together has no livestock. Therefore, only the 165 effective samples would be analyzed in this part.

The number of grassland is decreasing in grazing tenure of northwest pastoral. The samples show that the average household had only $54.5 \mathrm{hm}^{2}$ of grassland. The number of the grass-scale of less than $34 \mathrm{hm}^{2} \mathrm{was}$ accounted for $31.5 \%$, about $35-67 \mathrm{hm}^{2}$ was accounted for $38.2 \%$ and $68-135 \mathrm{hm}^{2}$ was accounted for $26.7 \%$. Animal husbandry and technical personnel had provided a reasonable stocking rate calculation unit in accordance with $1 \mathrm{hm}^{2}$ of 2 sheep, which means there was $31.5 \%$ of the livestock herds of no more than 71 sheep units, $38.2 \%$ of the herdsmen could not be more than 143 sheep units and $26.7 \%$ of the animal husbandry households could not be more than 286 sheep units. This represents $90 \%$ of the current herdsman overloaded.

Nevertheless, the aquaculture scale of herdsmen was still low. In the 165 samples, the maximum feeding scale of 200-400 sheep units, accounting for $26.7 \%$; the following is less than 100 , accounting for $26.1 \%$; more than 600 only accounting for $7.3 \%$. The main species of livestocks in pastoral were yak, for example, the breeding scale of more than 100 only was accounted for $16.3 \%$ and the number below 50 was accounted for $58.2 \%$. The households under investigation whose number below 20 and below 10 was accounted for $20.6 \%$ and $12.7 \%$ respectively, which was not only in the all small livestock households, but also was in the pastoral areas of poor households.

The livestocks in pastoral areas is not only the means of production to livestock-dependent pastoralists, but also a means of subsistence. According to data from animal husbandry sector, the per capita 60-80 sheep were needed in order to meet the pastoral needs. In the pastoral areas, the number of herdsmen can achieve this standard under the current scale farming is low. In the investigation of the 165 herdsmen, the number of herdsmen who have more than 60 sheep units per capita was 35 , accounting for $21.2 \%$, of whose over 80 sheep units per capita is 21 , accounting for $12.7 \%$. Nearly $80 \%$ of the herdsmen were in the minimum standards, and about 21 households whose sheep units per capita was below 10 among them, accounting for $12.7 \%$ of survey households.

\subsubsection{Animal Husbandry Productivity}

Over the years, the low productivity of grassland animal husbandry in pastoral areas mainly in a less slaughter rate (See Table 3).

The number of slaughter in Table 3 is the sum number of eaten and sale. The data shows that the slaughter number of livestocks which more than 20 took up $15.2 \%$ of households; $45.5 \%$ of the herdsmen slaughters livestock in the 10 below; another $13.3 \%$ of the herdsmen was no slaughter, that was not for sale nor eat. In terms of raising the amount of total slaughter weight basis, only $18.2 \%$ of the herdsmen slaughtered more than $20 \%$ of livestocks, nearly half of the herdsmen slaughtered below $10 \%$ or zero of livestocks. And some high slaughter rates of herdsmen households had some small livestocks.

\subsubsection{Improvement and Protection Action in Pasture}

Currently, most farmers still adhere to the traditional production methods relying on natural grassland for grazing, and less on to improve and protect the grassland. The household survey shows, only 55 pairs of grassland had been sowed and accounting for $32.4 \%$, including 38 of the sowing area of less than $0.7 \mathrm{hm}^{2}$. There were 54 herdsmen chosen "Yes" in the question of "rotational grazing or not", accounting for 31.8\%. With further asking, they understood that the rotational grazing was livestocks could be grazed in the summer and fall and pasture rotations in winter and spring, pasture rotation grazing and zoning with the season were very important to the latter for the rational utilization and protection of grassland.

\subsubsection{The Application of Modern Technology in the Production of Behavior}

The farmers whose possession of animal husbandry science and technology is very limited have been using traditional methods for a long time in Pasture. According to the survey of farmers, only 60 persons said they participated in the grass, raising or training in disease prevention and other production, which accounting for 
$35.3 \%$, the remaining $64.7 \%$ of herdsmen had not received such training. Therefore, the application of animal husbandry science and technology of production had less breeding; for example, only $8.8 \%$ of the herdsmen said they would go to animal husbandry and veterinary stations in the village for livestocks mating, the rest of the herdsmen's livestocks were mated by their own natural reproduction. Although such acts help herdsmen reduce production costs and make the costs lower, obviously are not having conducive to productivity.

\subsection{Consumer Behavior}

The level of income of farmers in north of Sichuan is generally low. The survey of households shows that per capita cash income was less than 1,000 RMB, accounting for 32.4\%; 1,000-2,000 RMB was accounted for $34.1 \%$; 2,000-3,000 RMB was accounted for $16.5 \%$; 3,000 or more was accounted for only $17.0 \%$. With low income, the life of most of herdsmen was mainly for consumption, and production and consumption were just in a tiny proportion. With the survey, we found that $57.6 \%$ of production cost of the herdsmen had a rate of $5 \%$ of total expenditure, only $5.3 \%$ of the herdsmen's production expenses took up more than $30 \%$ of total expenditures.

The living expenses of pastoralists were mainly for food, clothing, housing, household equipment, health care and education. On average, the housing expenses cost was the most, accounting for $36.2 \%$ of the total expenditure of life; and following was food expenditure, accounting for $21.3 \%$; and the least was medical treatment cost , accounting for $11.9 \%$, clothing cost was accounted for $10.8 \%$, children school fees cost was accounted for $7.2 \%$, motorcycle consumption, mobile consumption was accounted for $4.9 \%$, the family added equipment was accounted for $3.9 \%$, temple worship cost was accounted for $3.5 \%$, culture and entertainment consumption was accounted for only $0.3 \%$.

Above shows that housing, food and medical care and other life consumption were accounted for the majority consumption of herdsmen, and clothing, communication, household equipment, cultural and entertainment consumption reflected the "affluent" consumer was in a very low proportion. With households survey, almost $40 \%$ of the herdsmen consumption for the life of clothing, accounting for $10 \%$ of total spending; $31 \%$ of the herdsmen had no transportation and communication expenses; 152 herdsmen had no culture entertainment consumption, which accounting for $89 \%$. It shows the current spending of herdsmen could meet their basic needs and consumption is still in the stage of life.

\subsection{Social Behavior}

\subsubsection{Participation in Sports Activities}

There were 116 herdsmen involve the cultural and sports activities organized by the county every year, accounting for $68.2 \%$ of the samples "Do you participate in", 91 herdsmen participated occasionally or frequently, accounting for $53.5 \%$. Given the characteristics of their own cultural activities, it was generally more for young people to participate. Overall, the herdsmen kept a positive attitude towards the participation in sports activities.

\subsubsection{Social Security and Social Atmosphere}

For the multiple choice of investigation of public order, a theft phenomenon was reported by 113 people; fights were reported by 66 people. Cases of stealing cattle and horses in the county were discovered in the investigation of the provincial border area in particular. The herdsmen had expressed the great concern on crack down. For the multiple choice questionnaire of social morality, 87 people circled the phenomenon of gambling, 72 people circled the phenomenon of no showing filial respect to the elders, accounting for $51.2 \%$ and $42.4 \%$ respectively. "Rural civilization" remains to be further strengthened.

\subsubsection{Neighborhood}

The survey result of the pastoral relationships between the neighborhood shows: 98 people reflected the relationship between the neighborhoods was harmonious, 64 people thought the relationship between the neighborhoods was more harmonious, which accounting for $95.3 \%$ in together; 8 people thought the relationship was less harmonious and non-harmonious, which accounting for only $4.7 \%$. It shows that the relationship between herdsmen is very harmonious.

\subsubsection{Participation in the Democratic Management}

On the issue of participation in village meeting, 130 people often involved in meeting, accounting for $76.5 \%$; 17 people participated occasionally, accounting for $10 \%$; only 23 persons said that they never attended the meeting, accounting for $13.5 \%$. The survey of attitude of the answer on the election reflects that, 145 people thought that it was necessary to participate, accounting for $85.3 \% ; 11$ people considered it unnecessary to participate; 14 
people said that they did not care whether attend or mot. The results show that the majority pastoralists' attitudes on the "democratic management" are positive.

\subsection{Environmental Behavior}

"Clean village" on the environmental behavior is mainly embodied in three aspects.

Going to the toilet is the unique problem in the environmental problems of northwest pastoral areas, which reflects the ethnic particularity of the construction of new countryside in pastoral areas. The survey found that lack toilets in the Northwest Pastoral was a normal phenomenon, many herdsmen were still in the open pasture, roadside toilet hut, etc., affecting the "village capacity." In the question of "Do your home have toilets or not", the answer was: 28 homes had toilets, only accounting for $16.5 \%$; other herdsmen had no toilets at home. When being asked whether it is willing to repair the toilet, most herdsmen said it had used to the opened toilet, so did not want to build their own toilets; part of the farmers said if the government funded toilets, they would be willing to repair the toilets; another part of the herders said that toilet was optional. The reality is that some families have a toilet each; the toilet is also used for other purposes, not for its proper use.

Production and living waste disposal problems happened in most villages. The survey found that most village's livestock garbage were piled in open-air, and some villages piled them together, but some villages did not even have a central place pile, there was the garbage in everywhere, which seriously affected the cleanness of the villages. The villages in surveys had no facilities to deal with waste processing and no places, where the waste was just at most simple burning. At the same time, most herdsmen still used to throwing rubbish everywhere, and did not consciously center on piling up garbage and maintained weak awareness of the living environment. When the investigators asked whether they wish to centralize the garbage in order to beautify the cleanness of the village, most herdsmen were still welcome. However, if the herdsmen need the investment, or it will cause inconvenience to their daily lives, they would be in a degree of resistance.

Over the years, the herdsmen in northwest of Sichuan province and the nomadic living patterns are linked to the "nomadic" - tents affected, housing constructions have been built in anywhere since the 90s of last century with no planning and no disorganized, thus it is difficult to achieve "clean village".

\section{Influence Factors of the Behavior of Herdsmen}

\subsection{Lifestyle of Production}

Pastoral production and living habits greatly influence their behavior in the new orientation of rural development.

In the production aspect, the herdsmen who produce livestocks by using natural grassland for long time having no habits of investing in pasture improvement and building. At the same time, most herdsmen still follow the traditional idea, considering the number of livestock as a symbol of family wealth. The prevalence of this concept affects the rates of livestock slaughter, lengthens the feeding cycle and significantly increases the load-bearing pressure on the grass.

Some herdsmen's living habits not only affect their social behavior, but also affect their environmental behavior. For example, minority activities like singing, dancing, horsing and group activities, make herdsmen and villagers have positive in participate in sports activities and attend in the General Assembly, and the neighborhood relations are harmonious. The pastoral way of going to the toilet, littering and other acts are due to its long-standing habits development, and it will determine their appropriate environmental behavior.

Research of this topic area is in the Tibetan pastoral areas, the pastoralists are basically religious, and it is one of the important features that pastoral areas in northwest is different from other areas of new rural construction. The religious beliefs which in order to benefit living beings for the purpose, moral values, protections of plants and animals, prohibitions against killing, theft, fraud and other bad behaviors, no doubt have some positive impacts on the protections of the ecological and development of good social habits in the pastoral areas. However, the economic source of income of herdsmen are still taken from cows and sheep production and consumption, sheep slaughter, cattle slaughter and the sales would be unavoidable, which will resulted in a negative impact on the affluent life, and increased the pressures on the grass (Liu \& Zhang, 2008).

In addition, because of the religion, most of the herdsmen increase expenditures of "religious expenditures". In the surveyed by 170 households, 128 had religious expenditures, accounting for $75.3 \%$; the average expenditure of religious families was $758 \mathrm{RMB}$, accounted for $4.7 \%$ of total expenditure over the household equipment and other expenditure share, which closed to transportation and communication expenses. This phenomenon also affected the realization degree of "affluent". 


\subsection{The Quality of Pastoral Culture}

The education levels of herdsmen in northwest pastoral areas are generally low (See Table 4). The analyses on the relationship between education and the pastoral behaviors will be made according to the survey.

\subsubsection{Educational Level and Income Level}

Years of schooling and per capita cash income of the cross-analysis show that the three cultural levels of low-income (2,000 RMB per capita) account for a large proportion of all people, with the difference obvious, the cultural levels from low to high are $70.1 \%, 61.8 \%$ and $61.1 \%$ respectively. But there is little difference between two levels of education; more than 3,000 RMB in per capita income gap widened in the proportion of income levels from low to high cultural level are $14.4 \%, 18.2 \%$ and $27.8 \%$. So the education level has a major impact on the herdsmen's income.

\subsubsection{Education and Environmental behavior}

In the absence of schooling of 97 surveyed, only 9 herdsmen had toilets at home, the proportion is $9.3 \%$, while survey of 18 herdsmen who have middle school and higher education, there were 7 have toilets at home, the proportion is $38.9 \%$, much higher than the former. The Relationship between education and behavior of going to the toilet is significantly, this phenomenon should be seen as the result of education.

\subsection{Resource and Environmental Constraints}

The northwest pastoral has a high altitude and a cold climate and the grassland ecosystems are very fragile and very sensitive to external factors. Once the man-made disturbances broke the balance of ecological systems, it would cause a ecological damage to the environment and make ecosystem imbalance. With population growth, per capita grassland pastoral areas reduces, resource constraints increases, lawn serious overloads, coupled with effects of global climate warming, precipitation and drought prone, its easy leading serious grassland degradation (Yan et al., 2003)). "The development of production" achieves by herdsmen will be seriously affected. When being asked "Why not raising more cattle and sheep," $68 \%$ of herdsmen answered that the areas were limited for the grass or turf quality decline. In answering of the question "What do you hope the governments do", $41.6 \%$ of the herdsmen called for the strengthening grassland construction.

\subsection{The Weak Infrastructures}

Transportation, communication, electricity and other infrastructures are weak which are the important factors affecting of the behavior of herdsmen ( $\mathrm{Hu} \&$ Chen, 2006). Some herdsmen indicated that given the inconvenience of transport to transport cattle and sheep and other livestock out was difficult. Inconvenient transportation has hindered the herdsmen and communication from the outside world, and such acts like going out to work are also affected. In addition, some of the herdsmen did not often participate in sports activities or the General Assembly, the herdsmen said they lived too far and transportation was inconvenience. Because there is no electricity, many herdsmen have difficulties to use household appliances. Our surveys show that $35.9 \%$ of the herdsmen had complaints on the power status that the existing power of the family was often unbearable to the power over the household electrical appliances. Some herdsmen who had the capacity to pay a TV wanting buy a TV could only be set aside because of no power. Therefore, in answering of the question "What do you hope the governments do", there were $34.5 \%$ of the herdsmen hoped governments solve the water, electricity and road problems.

The lack distributions of media channels have prevented their ideology and awareness level changing. In the answer of "what channels do you heard the new rural construction from", only $23 \%$ of the people understood through radio, television and other media.

The inadequacy of related facilities is an important reason for why garbage and toilet issues exist so long. Very few public toilets exist in pastoral areas and there is no fixed trash and garbage, which contributed to the bad habit of pastoralists in some extent.

\subsection{Lack of Relevant Training}

Production skills and training of workers have also affected small farmers in the production of behavior. The survey showed that only $36.4 \%$ of the herdsmen participated in grass graze, keeping production, disease prevention and control training; training of workers was fewer, only $2.9 \%$ of the herdsmen expressed had participated in training. Thus, when herdsmen were asked "Do you have thought of going out for working", many people said that they could do nothing and would not get a job when going out. 


\subsection{The Ineffectively of Grassroots Work}

Currently, grass-roots cadres who coupled with the production life of pastoral in the poor quality of pastoral have a low pay. The slackness of pastoral grass-roots work result in the party and government policies can not be fully conveyed and the herdsmen's enthusiasm can not play fully, thus the construction of new countryside process would be affected. In the survey, the proportion of "none had heard of new construction "was accounted for $24.7 \%$ in rural areas; in the heard of the new countryside construction in rural areas, only $40.8 \%$ of the herdsmen was informed through grass-roots cadres; and most farmers did not know the content of new rural construction.

The weak grass-roots work has also led to some high cultural quality of the democratic management of farmers separated from outside. In general, the higher the educational level of democratic participation is, the higher level of recognition is. However, the cross-analysis of herdsmen's education and the attitude of election results show that the negative correlation (See Table 5): 97 people who did not attend school thought that the election did not matter or that there was no need to participate, which was a ratio of $7.3 \%$; the proportion of school 1-6 years of herdsmen who had the same idea was $20 \%$; while herdsmen in middle school and higher education were in the high proportion of $38.9 \%$.

The behavior of the herdsmen in participate in the General Assembly is similar to the behavior of participation in election. The herdsmen who often participate in General Assembly in the proportion of the villagers of the General Assembly were $84.2 \%, 76.4 \%$ and $47.1 \%$, which were from low cultural level to high cultural level. As the culture of high-quality pastoral groups play a leading role in all aspects, therefore, grassroots organizations and grass-roots work should be strengthened and the enthusiasm of this group should be play fully, which is a great significance to the construction of new countryside in pastoral areas.

\section{Conclusions and Recommendations}

Rural herdsmen are the most basic unit of the new rural construction of pasturing area in northwest Sichuan; their behavior will affect the orientation of the new process of rural development in pastoral areas directly. With the influence of their cultural quality, production and living habits, constraints on resources and environmental, poor infrastructure, lack of training and other factors, herdsmen's production of investment and scale are small, technology of animal husbandry is less modern and livestock production is low; the level of consumption in the survival stage is low; they participate in the democratic management of cultural activities positively and have a harmonious relationship with neighborhood, but the law and order are poor, civilization-building is not satisfactory; the production and life garbage are everywhere, what's more, the construction of settlement housing in a terrible mess, which is difficult to achieve "clean village."

Overall, some behaviors of herdsmen in construction of new rural are positive and some aspects of construction are negative. Therefore, we should take various measures to encourage positive factors, eliminate or transform the negative factors, and guide a new direction to benefit herdsmen in the construction of rural areas.

According to the actual situation in the pastoral areas, pastoral water, electricity, roads and other infrastructure projects should be strengthened to improve production and living conditions of herdsmen; investment in pastoral areas of science and technology should be increased. The herdsmen can be helped raise grass, feeding, disease prevention and control capacity to improve livestock productivity through technical training; the nine-year compulsory education should be perfected, while herdsmen's job training efforts should be strengthened to promote the part of the labor force from animal husbandry transfer to other industries, thus can reduce the amount of livestocks, ease the pressure on the grass and raise herdsmen's family economic level; the social security system in pastoral areas (particularly low-income groups) should be established and perfected gradually to pay attention to protect the basic living and the New Rural Cooperative Medical System; the grassroots organizations should be built to guide farmers to actively participation in the democratic management of high quality. In addition, the herdsmen's publicity and education on environmental protection should be strengthened through a variety of ways to enhance their ecological and environmental awareness.

\section{References}

Duan, W. Y. (2010). The Enthusiasm of Farmers Should be Fully Played in the New Rural Construction. Cang Sang, $3, \quad 48-49 . \quad$ [Online] Available: http://dlib.edu.cnki.net/kns50/detail.aspx?dbname=CJFD2010\&filename=CHSO201006026

Gu, D. Z. (2009). Study on the Dominant Position of Farmers in the New Rural Construction. Journal of Hunan University of Science and Engineering, 30(11), 113-114. [Online] Available: http://dlib.edu.cnki.net/kns50/detail.aspx?dbname=CJFD2009\&filename=JMLK200911032

Hu, T. Z., \& Chen, G. M. (2006). Building a new socialist countryside and consolidating the basement for a 
harmonious society. Journal of Chongqing University(Social Science), 12(2), 19-22. [Online] Available: http://d.wanfangdata.com.cn/Periodical_cqdxxb-shkx200602004.aspx

Liu, Y. Y., \& Zhang, W.X. (2008). Effects of Microcosmic Subjects' Behavior on Grassland Degradation and its Influencing Factors: Investigation of Herdsmen in Two Pastoral Countries of the Northwestern Sichuan Province. Journal of Sichuan Agricultural University, 26 (01), 81-84. [Online] Available: http://d.wanfangdata.com.cn/Periodical_scnydxxb200801017.aspx

Yan, Z. L., Zhou, K. H., Liu, W., \& Zhou, L. (2003). Preliminary discuss on grassland degradation in the source region of Yangtze and Yellow Rivers. Grassland of China, 25 (01), 73-78. [Online] Available: http://202.115.182.57/kns50/detail.aspx?QueryID=182\&CurRec=58

Zang, X. F. (2011). Study on the Main Reason for the Lack of Status of Farmers in the New Rural Construction. Journal of Shandong Agricultural University (Social Science Edition), 1, 53-61. [Online] Available: http://dlib.edu.cnki.net/kns50/detail.aspx?dbname=CJFD2011\&filename=SDND201101013

Ze, B., Dan, Q. M., Li,C. P., Tian, X. D., Zhao,Y., Deng, Z.Y.P., Lu, J., et al. (2008). Study on the Sustainable Development of the pasturing area of animal husbandry in northwest Sichuan. Grassland \& Animal Husbandry, 8, 1-14. [Online] Available: http://202.115.182.57/kns50/det-ail.aspx?Quer yID=131\&CurRec=1

Table 1. Basic characteristic of sample households

\begin{tabular}{|c|c|c|c|c|c|c|}
\hline Age & Below 20 & $21-30$ & $31-40$ & $41-50$ & Over 51 & Total \\
\hline Sample & 3 & 21 & 55 & 45 & 46 & 170 \\
\hline$\%$ & 1.8 & 12.4 & 32.3 & 26.5 & 27.0 & 100 \\
\hline Years of Education & 0 year & $1-3$ years & $4-6$ years & $7-9$ years & Over 9 years & Total \\
\hline Sample & 97 & 28 & 27 & 14 & 4 & 170 \\
\hline$\%$ & 57.1 & 16.5 & 15.8 & 8.2 & 2.4 & 100 \\
\hline
\end{tabular}

Source: our survey of the Pasturing Area in Northwest Sichuan.

Table 2. Herdsmen scale of operation

\begin{tabular}{|c|c|c|c|c|c|c|}
\hline Grassland area $\left(\mathrm{hm}^{2}\right)$ & $<7$ & $7-34$ & $35-67$ & $68-135$ & $>135$ & Total \\
\hline Sample & 7 & 45 & 63 & 44 & 6 & 165 \\
\hline$\%$ & 4.2 & 27.3 & 38.2 & 26.7 & 3.6 & 100 \\
\hline Sheep numbers & $<100$ & $101-200$ & $201-400$ & $401-600$ & $>600$ & Total \\
\hline Sample & 43 & 41 & 44 & 25 & 12 & 165 \\
\hline$\%$ & 26.1 & 24.8 & 26.7 & 15.2 & 7.3 & 100 \\
\hline Cattle numbers & $<20$ & $21-50$ & $51-100$ & $101-200$ & $>200$ & Total \\
\hline Sample & 34 & 62 & 42 & 20 & 7 & 165 \\
\hline$\%$ & 20.6 & 37.6 & 25.5 & 12.1 & 4.2 & 100 \\
\hline
\end{tabular}

Source: our survey of the Pasturing Area in Northwest Sichuan. 
Table 3. Livestock productivity

\begin{tabular}{|c|c|c|c|c|c|c|}
\hline Slaughter numbers & 0 & $1-10$ & $11-20$ & $21-30$ & $>30$ & Total \\
\hline Sample & 22 & 75 & 43 & 12 & 13 & 165 \\
\hline$\%$ & 13.3 & 45.5 & 26.1 & 7.3 & 7.9 & 100 \\
\hline $\begin{array}{c}\text { The proportion of slaughter } \\
\text { in total raising }\end{array}$ & 0 & $<5 \%$ & $5 \%-10 \%$ & $11 \%-20 \%$ & $>20 \%$ & Total \\
\hline Sample & 22 & 23 & 36 & 54 & 30 & 165 \\
\hline$\%$ & 13.3 & 13.9 & 21.8 & 32.7 & 18.2 & 100 \\
\hline
\end{tabular}

Source: our survey of the Pasturing Area in Northwest Sichuan.

Table 4. The cross-analysis of income levels of and education level

\begin{tabular}{|c|c|c|c|c|c|c|}
\hline \multirow{2}{*}{$\begin{array}{c}\text { Years of schooling } \\
\text { (years) }\end{array}$} & \multicolumn{4}{|c|}{ per capita cash income (RMB) } & \multirow{2}{*}{ Total } \\
\cline { 2 - 7 } & $<1000$ & $1000-2000$ & $2001-3000$ & $>3000$ & \\
\hline \multirow{2}{*}{0} & sample & 33 & 35 & 15 & 14 & 97 \\
\cline { 2 - 7 } & Proportion & $34.0 \%$ & $36.1 \%$ & $15.5 \%$ & $14.4 \%$ & $100.0 \%$ \\
\hline \multirow{3}{*}{$1-6$} & sample & 16 & 18 & 11 & 10 & 55 \\
\cline { 2 - 7 } & Proportion & $29.1 \%$ & $32.7 \%$ & $20.0 \%$ & $18.2 \%$ & $100.0 \%$ \\
\hline \multirow{3}{*}{$>6$} & Sample & 6 & 5 & 2 & 5 & 18 \\
\cline { 2 - 7 } & Proportion & $33.3 \%$ & $27.8 \%$ & $11.1 \%$ & $27.8 \%$ & $100.0 \%$ \\
\hline \multirow{2}{*}{ Total } & Sample & 55 & 58 & 28 & 29 & 170 \\
\cline { 2 - 7 } & Proportion & $100.0 \%$ & $100.0 \%$ & $100.0 \%$ & $100.0 \%$ & $100.0 \%$ \\
\hline
\end{tabular}

Source: our survey of the Pasturing Area in Northwest Sichuan.

Table 5. Pastoral education with the attitude of the cross-analysis of the election

\begin{tabular}{|c|c|c|c|c|c|}
\hline \multirow{2}{*}{\multicolumn{2}{|c|}{$\begin{array}{c}\text { Years of schooling } \\
\text { (years) }\end{array}$}} & \multicolumn{3}{|c|}{ participated in the attitude of village-level elections } & \multirow{3}{*}{$\begin{array}{c}\text { Total } \\
97 \\
\end{array}$} \\
\hline & & Necessary & Not necessary & Does not matter & \\
\hline \multirow{2}{*}{0} & Samples & 90 & 2 & 5 & \\
\hline & Proportion & $92.8 \%$ & $2.1 \%$ & $5.2 \%$ & $100.0 \%$ \\
\hline \multirow{2}{*}{$1-6$} & Samples & 44 & 8 & 3 & 55 \\
\hline & Proportion & $80.0 \%$ & $14.5 \%$ & $5.5 \%$ & $100.0 \%$ \\
\hline \multirow{2}{*}{$>6$} & Samples & 11 & 1 & 6 & 18 \\
\hline & Proportion & $61.1 \%$ & $5.6 \%$ & $33.3 \%$ & $100.0 \%$ \\
\hline \multirow{2}{*}{ Total } & Samples & 145 & 11 & 14 & 170 \\
\hline & Proportion & $100.0 \%$ & $100.0 \%$ & $100.0 \%$ & $100.0 \%$ \\
\hline
\end{tabular}

Source: our survey of the Pasturing Area in Northwest Sichuan. 